Eixo Temático: Relação entre Ciência, Educação e Cultura

ET-05-001

\title{
AGROTÓXICOS E AGROECOLOGIA: CONCONHECIMENTO PRÉVIO DOS ALUNOS DO ENSINO MÉDIO
}

Hadassa Carolinny Soares de Oliveira, Gabriel Henrique de Lima

Universidade Federal de Pernambuco - CAV, Vitória de Santo Antão-PE, Brasil E-mail: hadassalinnyoliveira@gmail.com.

http://dx.doi.org/10.21472/congrebio2016.et-05-001

\section{RESUMO}

A problemática dos agrotóxicos é um tema que vai além de questões ambientais, ela insere também questões de saúde pública, econômicas e políticas. Portanto esse é um tema que deve está presente na sala de aula para assim contribuir na construção do pensamento crítico do aluno. O objetivo deste trabalho foi avaliar os conhecimentos prévios dos alunos do $3^{\circ}$ ano do ensino médio de uma escola estadual do município de Vitória de Santo Antão - PE, Brasil, em relação aos agrotóxicos e as formas alternativas de produção de alimentos. Para isso utilizamos uma abordagem quanti-qualitativa. Como metodologia, distribuímos 60 questionários com perguntas subjetivas e objetivas. Dos resultados obtidos podemos dizer que a maioria dos alunos conhece ou já ouviu falar sobre os agrotóxicos, porém desconhecem as formas alternativas de produção de alimentos. Constatamos que é relevante abordar esse tema em sala de aula não apenas apontando os problemas causados pelos agroquímicos, mais também apresentar as formas alternativas de produção de alimentos.

Palavras-chave: Ensino, agrotóxico, agroecologia.

\section{INTRODUÇÃO}

A escola é o principal espaço de desenvolvimento crítico dos alunos, além de ser um ambiente de informação para a construção do conhecimento. Por essa razão, temas que envolvem a realidade do aluno deverão estar presentes na sala de aula, como por exemplo, a questão do uso de agrotóxicos na produção de alimentos. Apesar de o tema Agrotóxico aparecer vez ou outra nos meios midiáticos, muitas vezes ele não é abordado na escola. Quando é discutido em sala de aula, são levantadas apenas críticas em relação ao seu uso nas plantações, mas não são mencionadas as soluções, ou seja, não se fala das alternativas para a produção de alimentos saudáveis através da agroecologia e dos sistemas agroflorestais. Portanto, a escola pode representar um importante espaço de reflexão e resistência ao modelo de agricultura convencional caso considere seriamente em seu fazer pedagógico questões relacionadas aos processos de produção e consumo alimentar (Silva, 2011).

Discutir sobre os agroquímicos é importante para o aluno compreender melhor a temática e criar seus próprios conceitos em relação a ela. O aluno é um ser capaz de ter o seu próprio pensar, suas ideias, suas perguntas, ou seja, ele é capaz de argumentar e apontar alternativas e soluções para as situações (Carraro,1997). Segundo as orientações curriculares do ensino médio (PCNs, 2006):

É importante criar condições para que o aluno compreenda a necessidade de manejo adequado dos recursos naturais. Para que ele possa, assim, reconhecer os fatores que influenciam a qualidade de vida das populações humanas (p. 25). 
Ao esgrimir sobre os agrotóxicos com os alunos, é interessante que o professor faça uma interligação dos conhecimentos das matérias de biologia e química para que o aluno possa assimilar melhor o conteúdo. Além disso, ao apresentar os impactos socioambientais causados pela agricultura convencional, o professor também pode debater sobre ética, saúde, consumo, política e economia. Agregando múltiplas áreas, o professor evita repassar ao aluno uma visão fragmentada da ciência.

Apresentar soluções para os problemas é fundamental para que o aluno obtenha uma melhor contextualização do conteúdo, pois isso pode proporcionar ao aluno uma mudança de comportamento. A escola tem um papel a cumprir nesta perspectiva e trazer novas posturas diante da realidade (Carraro, 1997). A agroecologia e o sistema de agrofloresta aparecem como soluções para combater esse modelo de agricultura onde os defensivos químicos são utilizados causando diversos impactos negativos tanto na sociedade como no meio ambiente.

O objetivo desse trabalho foi avaliar os conhecimentos prévios dos alunos sobre os agrotóxicos e averiguar se eles conhecem as formas alternativas de produção com base na agroecologia.

\section{METODOLOGIA}

A pesquisa foi realizada com alunos do $3^{\circ}$ ano do ensino médio de escola estadual no município de Vitória de Santo Antão-PE. Para a coleta dos dados foram distribuídos 60 questionários com perguntas discursivas e objetivas sobre o tema.

Os dados foram analisados com enfoque qualitativo e quantitativo onde avaliamos a percentagem de alunos que tinham o conhecimento correto e equivocado do conceito de agrotóxico e se conheciam os tipos de produção sem o uso desses defensivos químicos.

\section{RESULTADOS}

Dos resultados obtidos, apenas 5\% do total de alunos não souberam definir o que é agrotóxico. $40 \%$ apresentaram uma definição equivocada acreditando que os agrotóxicos são produtos que auxiliam no crescimento, desenvolvimento e melhoramento da planta ou dos frutos, "É um produto que é utilizado nas plantas afim de melhora-las" e "São conservantes utilizados em frutas, verduras e legumes que também influenciam em seu desenvolvimento (crescimento e qualidade)". Já 55\% dos alunos souberam definir corretamente o que é o agrotóxico "São venenos usados para matar as pragas que prejudicam as plantações" $e$ "Agrotóxico é um produto químico que é usado em plantações e lavouras que serve para matar os insetos e outros tipos pragas." Como se pode observar, a maioria dos alunos sabem definir de uma forma genérica o que são os agrotóxicos, isso se deve as informações obtidas no cotidiano do aluno. Portanto é interessante observar como os meios midiáticos são importantes para a construção do conhecimento, porém devemos ter cuidado, pois muitas informações podem aparecer de forma distorcida de acordo com os interesses desses veículos de informação. Isso confirma que é fundamental que temas desse gênero sejam discutidos na escola já que esta se apresenta como um espaço de construção do pensamento crítico.

Dos alunos que sabem a definição de agrotóxico, 33\% conhecem uma forma alternativa de produção de alimentos sem o uso desses agentes químicos, "Os alimentos orgânicos onde não tem nenhuma química, ou seja, é natural", os outros 67\% desconhecem outro tipo de produção. Percebe-se que os alunos que apresentaram um conhecimento sobre as alternativas de produção de alimento, citaram apenas a produção de alimentos orgânicos, propriamente dita. Nota-se então que eles desconhecem a forma de produção, ou seja, como e quais sistemas realizam o cultivo de alimentos orgânicos (agroecologico e agroflorestal).

Dessa forma podemos dizer que faltam maior divulgação e discussão na escola com os alunos sobre as alternativas para solucionar os impactos socioambientais causados por esses defensivos químicos. É preciso abrir mais espaço para abordar temas que fazem parte da 
realidade do aluno apontando problemas, apresentando e discutindo soluções, dessa forma podemos contribuir para a construção de uma nova visão diante da realidade dos impactos causados pelos processos agroquímicos.

\section{CONCLUSÃO}

Com a nossa pesquisa constatamos que o tema Agrotóxico, por ser discutido tanto em meios midiáticos como na escola, a maior parte dos alunos já tem o conhecimento dessa temática, sendo capaz de defini-lo corretamente, porém observamos que grande parte desconhece uma solução para essa problemática. Portanto é importante abordar esse tema nas escolas já que ele que engloba questões de saúde pública, ambientais, econômicas e políticas, sem deixar de apresentar aos alunos as formas alternativas de cultivo de alimentos e controle de pragas.

\section{REFERÊNCIAS}

CARRARO, G. Agrotóxico e meio ambiente: Uma proposta de ensino de ciências e química. Química e Meio Ambiente - UFRGS, Instituto de Química- Área de Educação Química, 1997.

Orientações Curriculares de Ensino Médio. Ciências da Natureza, Matemática e suas Tecnologias. Conhecimentos de Biologia, 2006.

SILVA, E. R., DYSARZ, F.; FONSECA, A. B. Agroecologia em escolas urbanas alicerçando a perspectiva CTS no Ensino de Ciências, 2011. 